\title{
A mathematical model of the technology of extraction of copper from industrial slags
}

\author{
Kamolkhon Karimov ${ }^{1 *}$, Nodir Turakhodjaev, Azamat Akhmedov, and Sherzod Tashbulatov \\ Tashkent State Technical University named after I.A. Karimov, Tashkent, Uzbekistan
}

\begin{abstract}
The article substantiates the relevance and necessity of developing mathematical models in foundry production, as well as the problems and prospects of their use. Based on an analytical review of the world literature on foundry production, it was emphasized that in many studies of the authors and literary sources, not enough attention is paid to the development of mathematical models of the technological process of extracting non-ferrous metals from slag and industrial waste. A brief description of the developed technologies for the high-temperature treatment of industrial slags and waste, separation treatment in electric furnaces, and metals extracted from liquid slag is given. During the development and analytical implementation of the mathematical model, the developed technology for extracting copper from slags is presented as an research object. Based on the study of the dynamics of changes in the thermophysical properties of the components as a function of temperature, a mathematical model of high-temperature treatment of slags is compiled. This will allow you to predict the process of processing slags and the results obtained. Also, a mathematical model of the extraction of copper from the slag is compiled, taking into account the chemical properties of metal inclusions in the slag. This serves as the basis for automating the process of extracting copper from slags and waste products.
\end{abstract}

\section{Introduction}

The object of the study is industrial slags, as well as metal inclusions obtained using the developed technology for extracting copper from industrial slags. The purpose of the scientific work is to develop and analytically implement a mathematical model of the process of extracting copper from slags and industrial waste.

According to the developed technology, the slag treatment process is carried out with the immersion of the electrodes in a layer of a carbon-containing reducing agent at high temperatures, allowing the entire mass of the reducing agent to overheat over $1200-12500 \mathrm{C}[1]$.

The relevance of scientific research in this scientific direction is determined by two aspects of the problem: general scientific and engineering-applied.

In scientific terms, the actuality is that in most of the studies on foundry, not enough

* Corresponding author: kamolxon.karimov@gmail.com 
attention is paid to the mathematical modeling of the technological process to provide guidelines for implementing effective ways of using slag and not developed resourcesaving technology of recycling wastes.

In engineering and applied terms, it is relevant to substantiate and develop a technology for extracting copper from industrial slags to determine the numerical values of the desired parameters.

Currently, there is an acute shortage of copper raw materials for copper smelters. In this regard, the problem of involving digitalization and mathematical modeling in the processing of copper slags, which are foundry waste, is very relevant. Every year, the number of industrial slags and waste containing valuable components increases. This is because effective ways of using slags are not sufficiently implemented. Little attention is paid to the development of mathematical models of the technological process of extracting copper and non-ferrous metals from slag and industrial waste [2-4].

Researchers of the company "Kennecot copper Corporation" (USA) V. Donaldson, S. N. Sharma, and N. John.Emelisa developed a two-stage iterative method of copper recovery from the slag pyrometallurgical method. Researchers from Bayer AG (Germany) R. Baatz, G. Beilstein, D. Grenner, V. Keller, and D. Steinbach developed a technology for treating wastewater containing a copper catalyst formed as a result of the reaction of the dichlorobutane isomer [5-6]. Researchers of the company "Lonza Ltd." R. Thiel, K. Zinsstag, and G. Faschinger (Switzerland) have developed a method for extracting copper and other non-ferrous metals without consuming energy by gradually cooling organic components by carbonation. Studies of the company "SUMZ" (Japan) [7] found that when melting copper in a furnace without the use of a converter, the recoverability of copper increases, the cost of energy costs decreases, and at the same time, the amount of copper output in the matte increases.

Researchers from the CIS countries V. A. Vanyukov, A. N. Volsky, F. M. Loskutov, H. K. Avetisyan, V. Ya. Mostovich, S. I. Mitrofanov, A. M. Aksoy, and others determined the degree of copper loss through slag. Most of the research on losses comes from copper. According to V. A. Vanyukov's calculations, copper losses in the slag depend on the electrochromic orientation of the slag-matte relationship [8]. According to some researchers, the loss of copper in the slag can be mechanical and electrochemical (chemical and physical).

Also, large-scale research works are being carried out in Uzbekistan to extract copper and other components from industrial slags that ensure resource conservation. In particular, K. S. Sanakulov, A. A. Yusupkhodjaev, and S. R. Khudoyarov developed a technology for processing industrial slags [9]. According to S. Sanakulov, the main minerals of industrial slags are fayalite and magnetite.

Based on the analytical review of the literature sources, it should be noted that these studies do not provide recommendations for the introduction of effective ways of using slags and also do not develop a resource-saving technology for processing slags. To solve the above problems, it is necessary to research the preliminary treatment of slags, the enrichment of slags, and special high-temperature treatment technology development. In addition, it should also be emphasized that in these works, insufficient attention is paid to the development and analytical implementation of mathematical models of the technological process of extracting copper and non-ferrous metals from slag and industrial waste [9-10].

Following the problem statement, it is possible to formulate the following research goal: development of a technology for extracting copper and other non-ferrous metals from production slags; improvement of the technology for preparing for enrichment based on the separation method of production slags; development of a process for heat treatment of production slags in a reducing medium at an elevated temperature; development of a technology for extracting metal inclusions based on the creation of liquid slag at various 
temperatures; development and analytical implementation of mathematical models of the technological process of extracting copper and non-ferrous metals from slag.

\section{Methods}

When conducting research, the method of mathematical modeling based on algorithmization is widely used. It should be emphasized that the word "algorithm" comes from the name of the Central Asian scientist of the IX century Muhammad ibn Musa AlKhorezmi (born in Khorezm, Uzbekistan) about 783 - about 850). Al-Khorezmi is a great mathematician, astronomer, geographer, and historian. Thanks to Al-Khwarizmi, the terms "algorithm" and "algebra" appeared in mathematics.

Currently, no large-scale technological, environmental or economic project is implemented without mathematical modeling. A mathematical model is a set of equations or other mathematical relations that reflect the object's basic properties or phenomenon under study. Mathematical modeling must meet the following requirements: clear formulation of the basic concepts and assumptions based on experience, analysis of the models' adequacy, and guaranteed accuracy of computational algorithms [11].

In General, to produce General mathematical model equations, it seems necessary to know and use basic concepts and methods of mathematical analysis, analytic geometry, linear algebra, theory of functions of a complex variable, theory of probability and mathematical statistics, discrete mathematics, and carry out the necessary calculations in the framework of the constructed mathematical model. With the help of the developed mathematical model, it will be possible to solve a wide range of technological problems [12].

To create a mathematical model, an interpolation Lagrange polynomial was created. In other words, by bringing an algebraic system of equations, it is possible to express the definition of an unknown coefficient using the effective technology of multipliers.

$$
\left[\begin{array}{ccccc}
1 & x_{0} & x_{0}^{2} & \ldots & x_{0}^{n} \\
1 & x_{1} & x_{1}^{2} & \ldots & x_{1}^{n} \\
\vdots & \vdots & \vdots & \ddots & \vdots \\
1 & x_{n} & x_{n}^{2} & \ldots & x_{n}^{n}
\end{array}\right] \cdot\left[\begin{array}{c}
a_{0} \\
a_{1} \\
\vdots \\
a_{n}
\end{array}\right]=\left[\begin{array}{c}
y_{0} \\
y_{1} \\
\vdots \\
y_{n}
\end{array}\right]
$$

In the equation $n=3$, the vectorial equality will be

$$
\left[\begin{array}{ccc}
1 & T_{1} & T_{1}^{2} \\
1 & T_{2} & T_{2}^{2} \\
1 & T_{3} & T_{3}^{2}
\end{array}\right] \cdot\left[\begin{array}{l}
a_{1} \\
a_{2} \\
a_{3}
\end{array}\right]=\left[\begin{array}{l}
\lambda_{1} \\
\lambda_{2} \\
\lambda_{3}
\end{array}\right]
$$

Here,

$$
\begin{aligned}
& T_{1}=1000 C, T_{2}=1100 C, T_{3}=1200 C \\
& \lambda_{1}=32,6 \%, \lambda_{2}=35,8 \%, \lambda_{3}=38,5 \%
\end{aligned}
$$

the system of equations of an algebraic function will be equal to: 


$$
\left\{\begin{array}{l}
a_{1}+1000 a_{2}+1000^{2} a_{3}=32,6 \\
a_{1}+1100 a_{2}+1100^{2} a_{3}=35,8 \\
a_{1}+1200 a_{2}+1200^{2} a_{3}=38,5
\end{array}\right.
$$

Solving this system, $a_{1}=-26,9, a_{2}=0,0845, a_{3}=-0,000025$, the function of the efficiency of copper extraction with increasing temperature will have the following form:

$$
\lambda(T)=-26,9+0,0845 T-0,000025 T^{2} .
$$

Function (4) with a copper content of $0.64 \mathrm{~g}$ in $100 \mathrm{~g}$ of slag, the efficiency of extracting it from the slag will be determined by this equation. Similarly, if the copper content in the slag is $0.68 \mathrm{~g}$, the system of equations will take the form:

$$
\left\{\begin{array}{l}
a_{1}+1000 a_{2}+1000^{2} a_{3}=33,6 \\
a_{1}+1100 a_{2}+1100^{2} a_{3}=36,4 \\
a_{1}+1200 a_{2}+1200^{2} a_{3}=40,6
\end{array}\right.
$$

Solving this problem, $a_{1}=82,6, a_{2}=-0,119, a_{3}=0,00007$ we obtain, with an increase in temperature, the function of the efficiency of copper extraction under these conditions will be equal to:

$$
\lambda(T)=82,6-0,119 T+0,00007 T^{2} .
$$

Let us consider the problem of determining in the functional form the reduction of trivalent iron oxide of converter slag at a temperature of 1250 0C during its reduction process. As in the previous case, we determine the coefficients for composing the Lagrange interpolation polynomial. In this interpolation polynomial, time is an independent variable. The desired percentage of trivalent iron oxide is denoted by the function $\chi$.

Experimental studies have determined the following values.

According to this name,

$$
\left[\begin{array}{lllll}
1 & t_{1} & t_{1}^{2} & t_{1}^{3} & t_{1}^{4} \\
1 & t_{2} & t_{2}^{2} & t_{2}^{3} & t_{2}^{4} \\
1 & t_{3} & t_{3}^{2} & t_{3}^{3} & t_{3}^{4} \\
1 & t_{4} & t_{4}^{2} & t_{4}^{3} & t_{4}^{4} \\
1 & t_{5} & t_{5}^{2} & t_{5}^{3} & t_{5}^{4}
\end{array}\right] \cdot\left[\begin{array}{l}
a_{1} \\
a_{2} \\
a_{3} \\
a_{4} \\
a_{5}
\end{array}\right]=\left[\begin{array}{c}
\chi_{1} \\
\chi_{2} \\
\chi_{3} \\
\chi_{4} \\
\chi_{5}
\end{array}\right]
$$

Solving this linear system of algebraic equations, we obtain the following values: $a_{1}=25, \quad a_{2}=-2,966664, \quad a_{3}=-0,82, a_{4}=0,186667, a_{5}=-0,0096$. Taking this into account, we get the following desired functional dependency

$$
\chi(t)=25-2,966664 t-0,82 t^{2}+0,186667 t^{3}-0,0096 t^{4}
$$


Expression (8) is a continuous one-to-one time functional dependency. With the help of this dependence, it is possible to determine with great accuracy the decrease (percentage) of trivalent iron oxide of the converter slag during its reduction process at any arbitrary time.

In mathematical modeling of the process of melting copper slags in an electric arc furnace, the law of energy conservation for each element can be expressed by the following integral equation

$$
\int_{t_{1}}^{t_{2}}\left[\left.k \frac{d U}{d t}(x, \tau)\right|_{x=x_{2}}-\left.k \frac{d U}{d t}(x, \tau)\right|_{x=x_{1}}\right] d \tau+\int_{x_{1}}^{x_{1} t_{1}} \int_{t_{1}} F q v(\eta, \tau) d \eta \cdot d \tau=\int_{x_{1}}^{x_{2}} c \rho\left[U\left(\eta, t_{2}\right)-U\left(\eta, t_{1}\right)\right] d \eta .
$$

After several calculations during the transition $x_{1}, x_{2} \rightarrow x, t_{1}, t_{2} \rightarrow t$ in the limit position, we obtain the following differential equation of heat transfer:

$$
\frac{d U}{d y}\left(k(x) \frac{d U}{d t}\right)+F q v(x, t)=c \rho \frac{d U}{d x}
$$

$F q v(y, t)$ where is a function that characterizes the density of electrical sources when the energy flow changes in the internal slag layers.

By integrating the differential equation (10) under the exact boundary and initial conditions, it is possible to estimate the process of thermal transformation during the melting of slag in the furnace.

It should be particularly noted that the development and analytical implementation of mathematical models in the field of mechanical engineering materials science is very promising.

\section{Research results and Discussion}

Based on the conducted research, we present the following tables of numerical values of the main parameters. In the first stage of the study, primary melting was performed to extract metallic and non-metallic inclusions. To do this, in a gas furnace to a temperature of 1000$1200^{\circ} \mathrm{C}$ and an electric arc furnace to a temperature of $1600-1800^{\circ} \mathrm{C}$, the slag was melted using a flux [13].

Table 1. The efficiency of metal extraction depending on the exposure of molten slag at 100 minutes of exposure

\begin{tabular}{|c|c|c|c|c|}
\hline № & $\begin{array}{c}\text { Copper content } \\
\text { in the slag, } \\
\mathrm{g} / 100 \mathrm{~g}\end{array}$ & $\begin{array}{c}\text { The temperature } \\
\text { of the slag in the } \\
\text { furnace, }{ }^{0} \mathrm{C}\end{array}$ & $\begin{array}{c}\text { The time of } \\
\text { exposure of the } \\
\text { slag in the } \\
\text { furnace, minutes }\end{array}$ & $\begin{array}{c}\text { Efficiency of copper } \\
\text { recovery from slag, \% }\end{array}$ \\
\hline 1 & 0.64 & 1000 & 100 & 32.6 \\
\hline 2 & 0.68 & 1000 & 100 & 33.6 \\
\hline 3 & 0.64 & 1100 & 100 & 35.8 \\
\hline 4 & 0.68 & 1100 & 100 & 36.4 \\
\hline 5 & 0.64 & 1200 & 100 & 40.6 \\
\hline 6 & 0.68 & 1200 & 100 & \\
\hline
\end{tabular}


Table 2. The efficiency of metal extraction depending on the exposure of molten slag at 120 minutes of exposure

\begin{tabular}{|c|c|c|c|c|}
\hline № & $\begin{array}{c}\text { Copper content } \\
\text { in the slag, } \\
\mathrm{g} / 100 \mathrm{~g}\end{array}$ & $\begin{array}{c}\text { The temperature } \\
\text { of the slag in the } \\
\text { furnace, }{ }^{0} \mathrm{C}\end{array}$ & $\begin{array}{c}\text { The time of exposure } \\
\text { of the slag in the } \\
\text { furnace, minutes }\end{array}$ & $\begin{array}{c}\text { Efficiency of } \\
\text { copper recovery } \\
\text { from slag, } \%\end{array}$ \\
\hline 1 & 0.64 & 1000 & 120 & 30.3 \\
\hline 2 & 0.68 & 1000 & 120 & 31.4 \\
\hline 3 & 0.64 & 1100 & 120 & 32.6 \\
\hline 4 & 0.68 & 1100 & 120 & 33.4 \\
\hline 5 & 0.64 & 1200 & 120 & 34.6 \\
\hline 6 & 0.68 & 1200 & 120 & 38.2 \\
\hline
\end{tabular}

According to the results of the studies shown in the tables, it can be seen that the exposure of the slag at a temperature of $12000 \mathrm{C}$ gives a greater effect with the extraction of $38.2 \%$ of copper from its concentration in the slag of $0.68 \%$. At the same time, with a shutter speed of up to 100 minutes, the efficiency is higher, but with a shutter speed of 120 minutes, the efficiency is reduced. The reason for this may be the chemical processes between the metal inclusions during overexposure of the slag. Therefore, the slag superheated to a temperature of 1200 0C must be kept for up to 100 minutes, and it is advisable to remove metal inclusions during this period.

The obtained numerical data for the extraction of metallic and non-metallic inclusions from the slag produced a primary remelting in the future. At the same time, the remelting temperature was brought to $1600-18000 \mathrm{C}$ in an electric arc furnace, and the exposure time was $60-120$ minutes [14].

\section{Conclusions}

Based on the conducted research, the following conclusions can be drawn:

1. The technology of extraction of copper from industrial slags has been developed. Improvement of the technology of preparation for enrichment based on the method of separation of industrial slags.

2. The heat treatment process of industrial slags in a reducing medium at a special temperature has been developed.

3. Technology for extracting metal inclusions based on the creation of liquid slag at different temperatures has been developed.

4. It is noted that the literature does not sufficiently pay attention to the development of mathematical models of the technological process of extracting non-ferrous metals from slag and industrial waste.

5. The relevance and prospects of the widespread use of mathematical modeling methods in foundry production are substantiated.

6. A mathematical model of the technological process of extracting copper from slag is developed and analytically implemented. At the same time, systems of algebraic equations, integral and differential equations are compiled and analytically implemented. 


\section{References}

1. Grachev V., Turakhodjaev, $N$. Influence of liquid aluminum alloy treatment at temperatures up to ${ }^{0} \mathrm{C}$ in terms of the alloy structure and gas aluminum oxides content, International Journal of Mechanical Engineering and Technology, 9(7), pp. 489-495. (2018).

2. Zvonarev S. V. Fundamentals of mathematical modeling. Yekaterinburg.(2019).

3. Introduction to mathematical modeling. / edited by P. V. Trusov. Moscow. Logos, (2007).

4. Korotkiy A. I., Halperin, L. G. Mathematical modeling. Yekaterinburg, (2005).

5. J. V.Donaldson, S. N. Sharma, and N. J. Temelis (US Patent 4,032,327, June 28, 1977; Kennecott Konnep Corporation»),

6. R. Baatz, G. Beilstein, D. Grenner, W. Keller, and D. Steinbach (US patent 4,070,405, January 24; Bayer AT), G. (1978).

7. Hajime Nakazawa, Ichikawa; Hiroshi Naruse, Kokubunji, all of Japan Assignee: United States Patent, Arakatsu et al. 4,022,686 Flotation process for copper ores and copper smelter slags/ Inventors: Akira Arakatsu, Tokyo; Sumitomo Metal Mining Co., Limited, Japan Filed: Feb. 20, 1976[21] Appl. No.: 659,965. May 10, (1977).

8. Nodir Turakhodjaev, Shukhrat, C., Jamaliddin, K., ...Jaloliddin, E., Kulmukhammad, C. Ways to increase the strength of the surface of the parts//Journal of Critical Reviews, 7(11), pp. 380-386. (2020).

9. Sanakulov K. S., Khasanov A. S. Processing of copper production slags-Tashkent: FAN, 2007. -256 p.Metals The Metallurgy of the Common, Gold, Silver, Iron, Copper, Lead, and Zinc, by Leonard S. Austin. (2012).

10. Samadov A.U., Matkarimov S.T., Khudoyarov S.R., Berdiyarov B.T. Studying methods of extraction iron and its compounds from steel-smelting slags // Proceedings of the international conference on integrated innovative development of Zarafshan region: achievements, challenges and prospects, - pp. 182-184. Navoi, (2017).

11. Karimov K., Akhmedov A., Kushimov B., Yuldoshev B. Justification, development of a new technology and design for drying seeds of desert fodder plants. IOP Conf. Series: Materials Science and Engineering 883 (2020)

12. Karimov K., Khudjaev M. and etc. Simulation of fluid outflow from a channel with complex geometry. E3S Web of Conferences 224, 02003 (2020), TPACEE-2020. Sankt-Peterburg. https://doi.org/10.1051/e3sconf/202022402003.

13. Wang, Y., Zhang, S., Wu, R., ...Liu, M., Mardonakulov, S. Concurrently improving uniform elongation and strength of ultrafine-grained Al-2Li alloy// Materials Science and Engineering A, 792, 139848, (2020).

14. Nodir, T., Sherzod, T., Ruslan, Z., Sarvar, T., and Azamat, B. Studying the scientific and technological bases for the processing of dumping copper and aluminum slags//Journal of Critical Reviews Vol 7, Issue 11, ISSN- 2394-5125 Volume 7, Issue $5,(2020)$

15. Bocharov V. A., Ignatkina V. A., Puntsukova B. T. Technological modes of enrichment of technogenic mineral raw materials, Mining information and analytical Bulletin (scientific and technical journal) - No. 9. - pp. 232-241. (2009) 